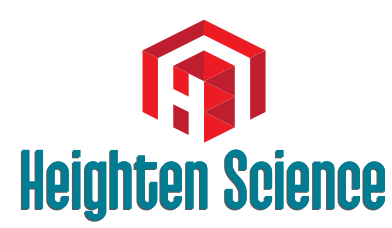

P U B L I C A T I O N S Corporation

\title{
Progress in the development of
} Lipoplex and Polyplex modified with Anionic Polymer for efficient Gene Delivery

\author{
Yoshiyuki Hattori* \\ Department of Drug Delivery Research, Hoshi University, Ebara 2-4-41, Shinagawa-ku, Tokyo \\ 142-8501, Japan
}

\begin{abstract}
*Address for Correspondence: Dr. Yoshiyuki Hattori, Department of Drug Delivery Research Hoshi University, Ebara 2-4-41, Shinagawa-ku, Tokyo 142-8501, Japan, Tel/Fax: +81 35498 5054; Email: yhattori@hoshi.ac.jp

Submitted: 29 June 2017

Approved: 21 July 2017

Published: 24 July 2017
\end{abstract}

Copyright: @ 2017 Hattori Y. This is an open access article distributed under the Creative Commons Attribution License, which permits unrestricted use, distribution, and reproduction in any medium, provided the original work is properly cited

A) Check for updates

\section{ABSTRACT}

Nucleic acid-based therapy has become an increasingly important strategy for treating a variety of human diseases. In systemic therapy, a therapeutic gene must be delivered efficiently to its target tissues without side effects. To deliver a therapeutic gene such as plasmid DNA (pDNA) or small interfering RNA (siRNA) to target tissues by systemic administration, cationic carriers such as cationic liposomes and polymers have been commonly used as a non-viral vector. However, the binary complex of therapeutic gene and cationic carrier must be stabilized in the blood circulation by avoiding agglutination with blood components, because electrostatic interactions between positively charged complexes and negatively charged erythrocytes can cause agglutination, and the agglutinates contribute to high entrapment of the therapeutic genes in the highly extended lung capillaries. One promising approach for overcoming this problem is modification of the surface of cationic complexes with anionic biodegradable polymers such as hyaluronic acid, chondroitin sulfate, or polyglutamic acid. As another approach, we recently developed a sequential injection method of anionic polymer and cationic liposome/therapeutic gene complex (cationic lipoplex) for delivery of a therapeutic gene into the liver or liver metastasis. In this review, we describe recent advances in the delivery of therapeutic genes by lipid- and polymer-based carrier systems using anionic polymers.

\section{INTRODUCTION}

Nucleic acid-based therapy (gene therapy) has recently received much attention as a therapeutic methodology for a number of acquired and inherited diseases [1]. Nucleic acid-based therapy can be defined as the treatment of a disease by the transfer of a therapeutic gene (DNA or RNA) into target tissues for expression or suppression of a gene related to the disease process of interest. Nucleic acid-based therapeutics include plasmid DNA (pDNA), small interfering RNAs (siRNAs), and microRNAs (miRNAs). pDNA for gene expression systems, which is circular, double-stranded DNA molecule, contains a complementary DNA coding for the therapeutic gene and several other genetic elements such as enhancers, promoters, and polyadenylation sequences to control transcription. Recombinant pDNA carrying therapeutic gene can produce the therapeutic protein by introduction into cells. In contrast, both siRNA and miRNA interact with mRNAs, typically triggering mRNA degradation. siRNAs, which are small double-stranded RNAs, are substrates for the RNA-induced silencing complex (RISC), and they suppress the expression of a target gene by triggering specific degradation of the complementary mRNA sequence [2]. miRNAs, small single stranded endogenous RNAs, induce translational repression by blocking mRNA translation and triggering degradation of the mRNA after incorporation into the RISC [3]. The RISC uses the siRNA or miRNA as a template for recognizing a complementary mRNA. Specific siRNA- and 
miRNA-mediated target gene degradation is expected to be used in the treatment of various diseases. However, these nucleic acid-based medicines are hindered by disadvantages related to their intrinsic properties such as easy degradation by serum nucleases and low cellular uptake due to repulsion by the negatively charged cell membrane [4-6]. Therefore, the development of suitable vectors (carriers) for efficient and stable delivery of nucleic acid-based medicines to the target cells is an important issue.

Vectors for the delivery of nucleic acid-based medicine can be divided into viral and non-viral systems. Viral vectors, such as retroviruses, adenoviruses, adeno-associated viruses, and several other viral types, are efficient in transfection [1,7], but they have risks to the host due to the immunogenicity of viral proteins, the potential for oncogenesis due to chromosomal integration, and the generation of infectious viruses due to recombination [8]. In contrast, non-viral vectors have many advantages, such as the ease of modifying the surface of the vector for tissue-specific targeting, their lack of immunogenicity, relative safety, and relative ease of large-scale production. Therefore, non-viral vectors are an attractive alternative method for clinical gene therapy $[9,10]$. Among non-viral vectors, cationic liposomes and cationic polymers have been more commonly used [11-13], because they can easily form complexes with the DNA or RNA molecules via the negatively charged phosphate groups of nucleic acids. Cationic polymer/therapeutic gene complexes (cationic polyplexes) or cationic liposome/therapeutic gene complexes (cationic lipoplexes) can improve the cellular uptake of nucleic acid-based therapeutics by interaction with the negatively charged cell surface. Advantages of using cationic polyplexes or lipoplexes include protection of the therapeutic gene from serum nucleases.

In systemic gene therapy, a nucleic acid-based therapeutics must be delivered efficiently to the target tissue. However, it has been reported that cationic lipoplexes or polyplexes accumulated mostly in the lung after intravenous injection $[14,15]$. This accumulation of the complexes in the lung is the result of agglutination caused by electrostatic interactions between positively charged complexes and negatively charged erythrocytes [16]. The agglutinates contribute to the high entrapment of lipoplexes in the highly extended lung capillaries and induce accumulation predominantly in the lung [17]. Therefore, polyplexes and lipoplexes must be stabilized in the blood by avoiding agglutination with blood components. In liposomal gene delivery, PEGylation on the surface of cationic lipoplexes (PEG-modified lipoplexes) can decrease accumulation in the lung by avoiding association with blood components; however, PEGylation also inhibits cellular uptake of lipoplexes in target tissues and abolishes the expression of therapeutic gene from pDNA or silencing effect of target gene by siRNA in all organs owing to the high stability of lipoplexes, which had been termed the PEG dilemma $[18,19]$.

One promising approach for overcoming this problem is electrostatic encapsulation or surface-modification of cationic lipoplexes or polyplexes with anionic biodegradable polymers such as hyaluronic acid (HA), chondroitin sulfate (CS), or polyglutamic acid (PGA) (Figure 1), because such anionic complexes can prevent agglutination with blood components after systemic injection. In this review, we describe recent advances in the delivery of nucleic acid-based therapeutics by non-viral vectors using anionic polymers.

\section{Polyplexes and lipoplexes modified with hyaluronic acid}

HA is non-sulfated, unbranched glycosaminoglycan composed of alternating residues of $\beta$-D-(1-3) glucuronic acid and $\beta$-D-(1-4)- $N$-acetylglucosamine (Figure 1 ), and it is used as a material for stealth behavior and tumor-targeted delivery (Table 1). For gene delivery, HA is usually coated onto surface of cationic lipoplexes or polyplexes by electrostatic interactions to shield the positive charge. HA is a prominent 


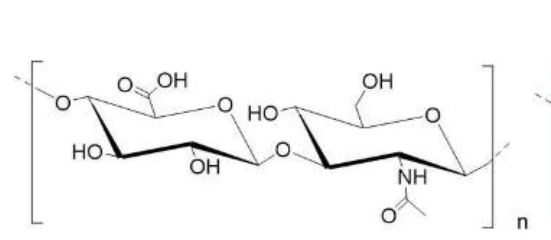

HA

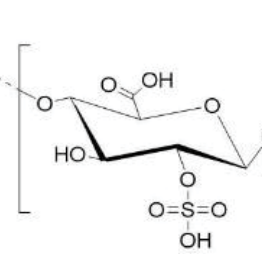

Heparin $\mathrm{OH}$

$\underset{S=O}{\mathrm{O}}=0$

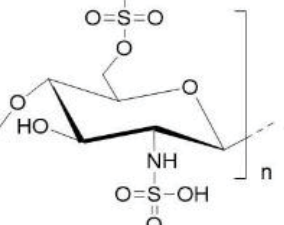

O

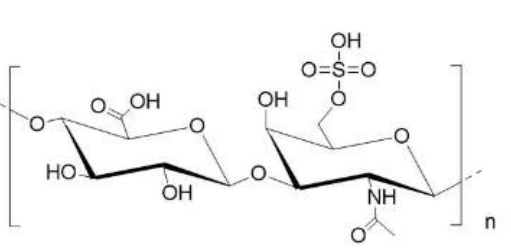

CS<smiles>CC(CCC(=O)C(CCC(=O)O)NC(C)(C)C)NC(C)(C)C</smiles>

$\alpha \mathrm{PGA}$

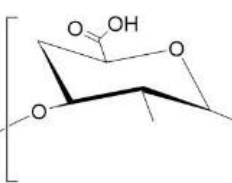

Pectin

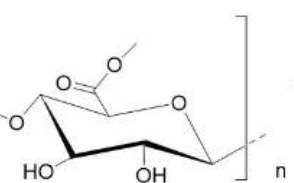

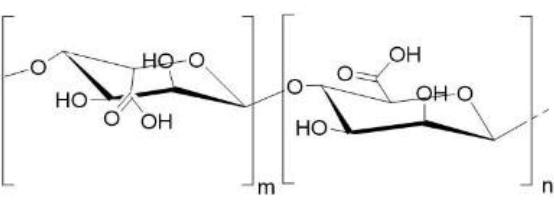

Alginic acid

Figure 1: Representative anionic polymers used for coating of lipoplexes and polyplexes. CS: chondroitin sulfate C, HA: hyaluronic acid, yPGA: poly- $\mathrm{Y}-$ glutamic acid, aPGA: poly-a-glutamic acid.

Table 1: Polyplexes or lipoplexes with hyaluronic acid (HA) or HA conjugate for gene delivery.

\begin{tabular}{|c|c|c|c|}
\hline Nucleic acid & HA or HA conjugate & $\begin{array}{l}\text { Cationic polymer or } \\
\text { liposome }\end{array}$ & Reference \\
\hline pDNA & $\mathrm{HA}$ & Lipofectamine 2000 & [24] \\
\hline pDNA & $\mathrm{HA}$ & Chitosan & {$[25,26]$} \\
\hline pDNA & $\mathrm{HA}$ & Polyethylenimine (PEI) & [28-30] \\
\hline pDNA & $\mathrm{HA}$ & PAMAM & [34] \\
\hline pDNA & HA-PEI & - & {$[46]$} \\
\hline siRNA & $\mathrm{HA}$ & DOTAP/DOPE liposome & [23] \\
\hline siRNA & $\mathrm{HA}$ & Poly-L-arginine & [35] \\
\hline SiRNA & $\mathrm{HA}$ & Chitosan-PEI & [32] \\
\hline siRNA & $\mathrm{HA}$ & Chitosan-g-PEG & [27] \\
\hline siRNA & $\mathrm{HA}$ & PAMAM & [33] \\
\hline siRNA & $\mathrm{HA}$ & PLGA-PEI & [31] \\
\hline siRNA, miRNA & HA-PEI & - & {$[41-45,47]$} \\
\hline SiRNA & HA-DOPE & DE/DOPE liposome & [36-39] \\
\hline siRNA & HA-DOPE & DOTAP/DOPE liposome & {$[40]$} \\
\hline SiRNA & HA-DOPA & Calcium & {$[48]$} \\
\hline SiRNA & HA-siRNA & $\mathrm{PEI}$ & [49] \\
\hline Antisense DNA & HA-antisense DNA & Protamine & [50] \\
\hline
\end{tabular}

pDNA: plasmid DNA, siRNA: small interfering RNA, miRNA: microRNA, HA: hyaluronic acid, DOTAP: 1,2-dioleoyl-3trimethylammonium-propane, DOPE: 1,2-dioleoyl-sn-glycero-3-phosphoethanolamine, DE: [2-(2,3-didodecyloxypropyl) hydroxyethyl]ammonium bromide, DOPA:3,4-dihydroxy-L-phenylalanine, PAMAM: poly (amido amine), PEG: polyethylene glycol, PLGA: poly(lactic-co-glycolic acid).

component of the microenvironment in most malignant tumors, and CD44 is the major receptor for HA. The binding of HA to the extracellular domain of CD44 promotes its interaction with certain cytoskeletal proteins $[20,21]$ and stimulates a variety of tumor cell-specific functions and tumor progression [22]. Therefore, HA is used for targeting tumor cells that overexpress CD44 on the cell surface.

In liposomal delivery systems for pDNA or siRNA, the cationic lipids 1,2-dioleoyl-3-trimethylammonium propane (DOTAP) and 1,2-di-O-octadecenyl3-trimethylammonium propane (DOTMA) have frequently been used, along with 1,2-dioleoyl-sn-glycero-3-phosphoethanolamine (DOPE) and cholesterol (Chol) as a helper lipid (Figure 2). DOPE affects the structural transition of cationic liposomes at acidic $\mathrm{pH}$ in late endosomes after cellular uptake via endocytosis, which promotes 
endosomal escape of siRNA or pDNA lipoplexes. In liposomal delivery, HA coating (Figure 3A) could shield the positive charges of DOTAP/DOPE lipoplexes with siRNA and specially help to target and enter tumor cells without affecting normal tissues [23]. Lipofectamine 2000 is a commercially available liposomal transfection reagent. Lipofectamine 2000 lipoplexes were successfully coated with HA via electrostatic interaction (Figure 3A), and the HA coating did not decrease gene transfection [24].

Chitosan is an $\mathrm{N}$-deacetylated derivative of chitin, and polycationic linear polysaccharide composed of $\beta$-(1-4)-linked D-glucosamine and N-acetyl-Dglucosamine (Figure 4). The electrostatic interaction between chitosan and nucleic acid can lead to the formation of a stable complex of chitosan with pDNA or siRNA. A ternary complex of pDNA/chitosan/HA (Figure 5A), exhibited higher transfection
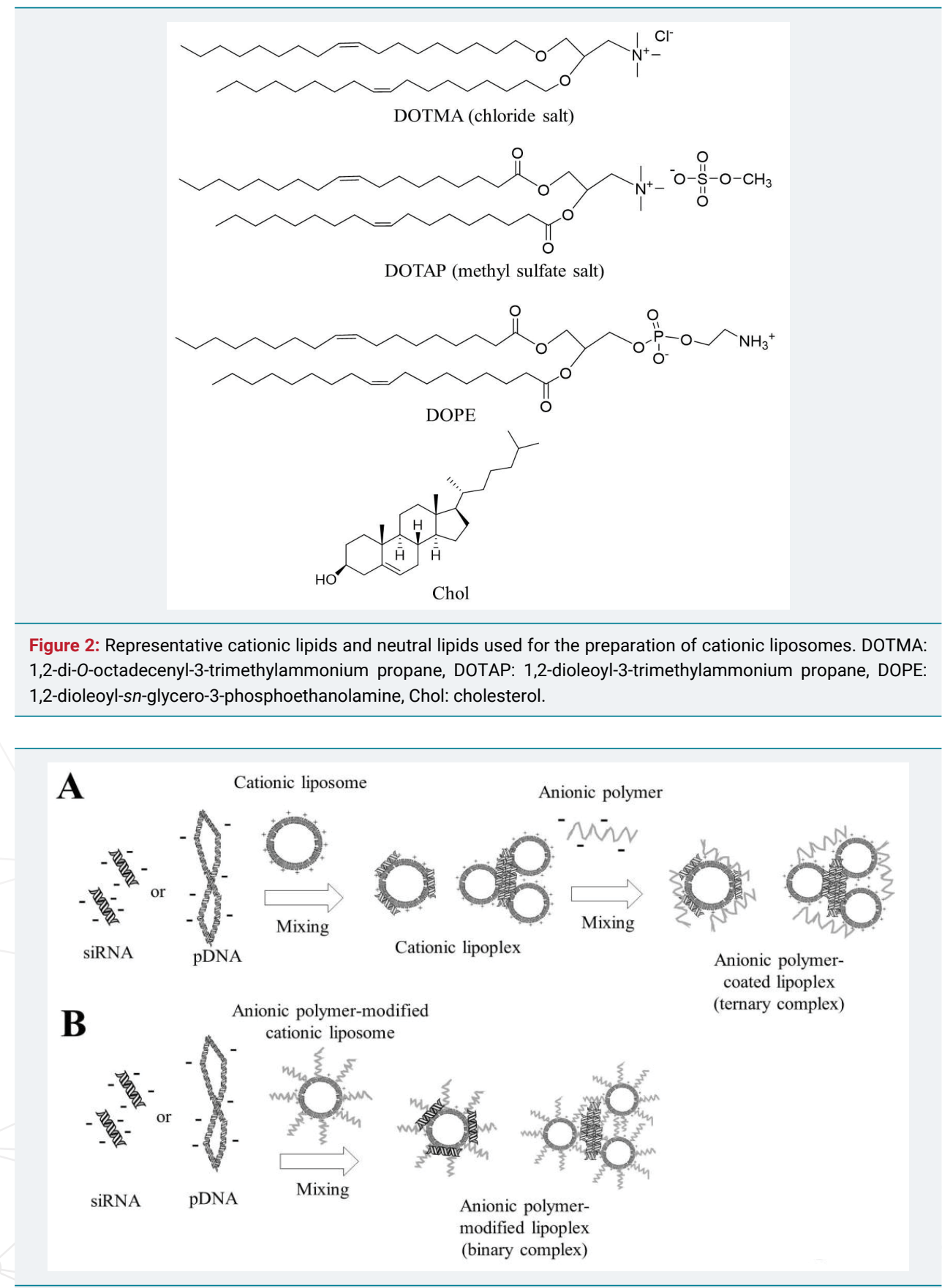

Figure 3: Preparation of anionic polymer-coated lipoplexes. In A, cationic lipoplexes were prepared with mixing plasmid DNA (pDNA) or small interfering RNA (siRNA) with cationic liposomes, and then these were coated with anionic polymer by electrostatic interactions. In $\mathrm{B}$, cationic liposomes were modified with anionic polymer-lipid conjugate, and then anionic polymer-modified liposomes interacted electrostatically with pDNA or siRNA. 
efficiency in primary chondrocytes than a binary complex of pDNA/chitosan [25], and this promoted chondrocyte proliferation by transfection of a pDNA encoding the transforming growth factor (TGF)- $\beta 1$ gene [26]. Furthermore, a ternary complex of nucleic acid/chitosan- $g$-poly(ethylene glycol) (CS- $g$-PEG)/HA was an effective carrier for delivery of both siRNA and pDNA, eliciting a biological response with minimal cytotoxicity [27].
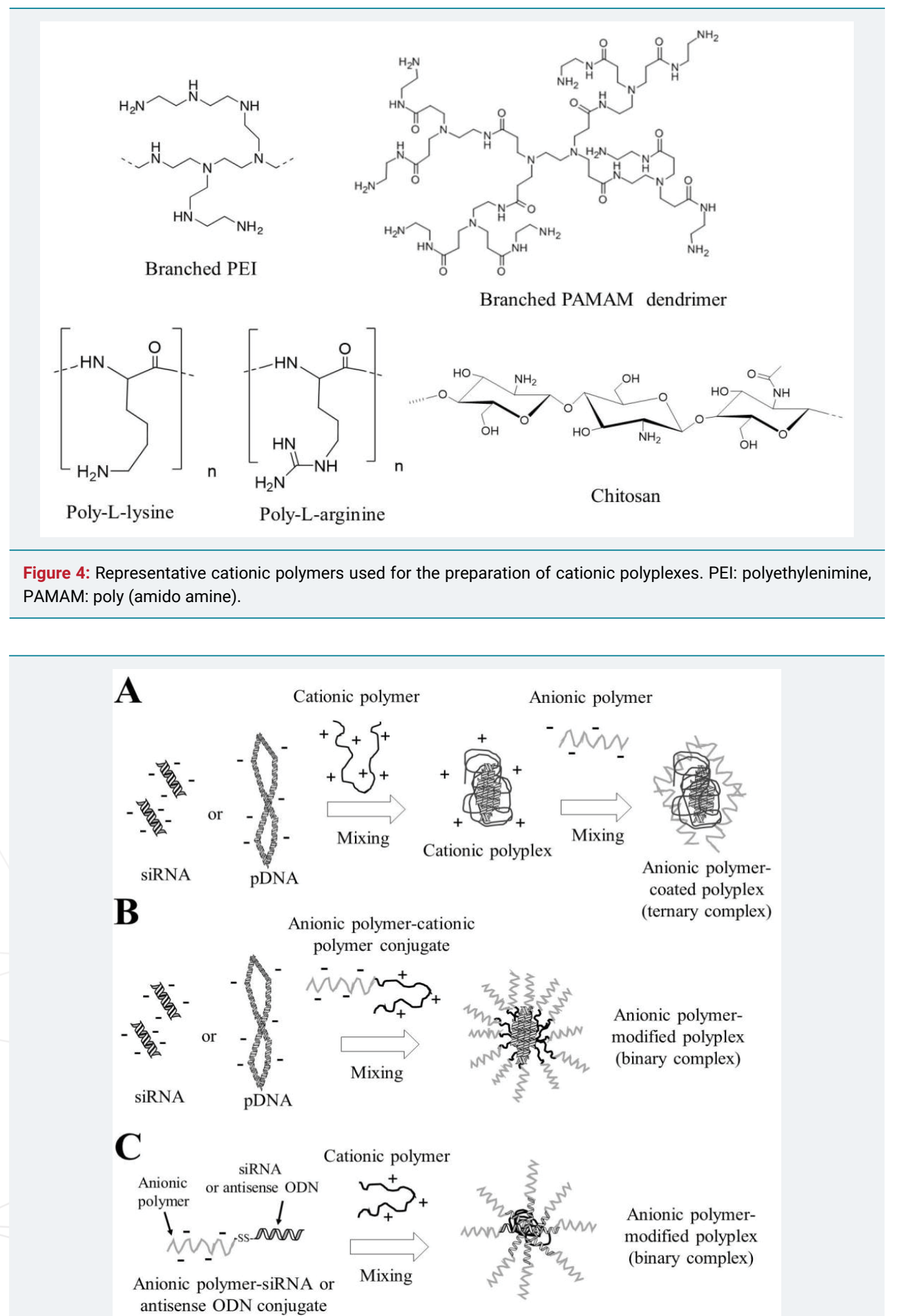

Anionic polymermodified polyplex (binary complex)

Figure 5: Preparation of anionic polymer-coated polyplexes. In A, cationic polyplexes were prepared with mixing of plasmid DNA ( $\mathrm{pDNA}$ ) or small interfering RNA (siRNA) with cationic polymers, and then they were coated with anionic polymer by electrostatic interactions. In $\mathrm{B}$, anionic polymer-cationic polymer conjugates interacted electrostatically with pDNA or siRNA. In C, anionic polymer-siRNA conjugates or anionic polymer-antisense oligodeoxynucleotide (ODN) conjugates via a reducible disulfide linkage interacted electrostatically with cationic polymers. 
Polyethylenimine (PEI) and poly(amido amine) (PAMAM) polymer possess intrinsic endosomolytic activity due to the residues of these polymers being unprotonated at physiological $\mathrm{pH}$, making them efficient "proton sponges". Upon acidification in endosomes after endocytosis of PEI or PAMAM polyplexes, further protonation of the polymers occurs, which triggers chloride influx, resulting in osmotic endosome swelling, destabilization and rupture of endosomal membranes, and escape of the polyplexes from endosomes into the cytoplasm. PEI is a cationic polymer with repeating units composed of an amine group and a two-carbon aliphatic spacer $\left(\left(\mathrm{C}_{2} \mathrm{H}_{5} \mathrm{~N}\right)_{\mathrm{n}}\right)$ (Figure 4), and it has in linear and branched forms, which are both efficient in delivering pDNA or siRNA. Ternary complexes of pDNA/PEI/HA (Figure 5A) showed a high gene expression level in tumors after intravenous injection into tumor-bearing mice [28-30]. Lie et al. reported that a poly (lactic-co-glycolic acid)-polyethylenimine (PLGA-PEI)/hypoxia-inducible factor (HIF)-1 $\alpha$ siRNA complex covered with HA could efficiently decrease the level of HIF-1 $\alpha$ expression in tumor cells [31]. In addition, a ternary complex of siRNA/PEI-grafted chitosan oligonucleotide/HA (Figure 5A) was used as an effective carrier to endometriotic lesion via binding of HA to CD44 [32].

PAMAM is a linear or hyper-branched dendrimer made of repetitive subunits of amide and amine (Figure 4). Chen et al. reported that a ternary complex siRNA/ PAMAM/HA (Figure 5A) could deliver siRNA into human breast tumor MDA-MB-231 cells that overexpressed CD44 [33]. Gu et al. demonstrated that incorporation of HA in pDNA/PAMAM polyplexes (Figure 5A) resulted in dramatically improved tumor accumulation of pDNA in pulmonary tumor (mouse melanoma B16-F10)-bearing mice [34]. Moreover, intratumoral injection of ternary complexes of siRNA/poly-Larginine/HA (Figure 5A) significantly reduced the expression of a target gene in tumor tissues [35].

HA can also be conjugated to lipids (Figure 3B) or polymers (Figure 5B) using chemical linkers [36-41]. HA-DOPE conjugate can be obtained through the creation of an amide bond between the carboxylic groups of HA and the amino group of DOPE [37]. Inclusion of HA-DOPE conjugates into cationic liposomes composed of [2-(2,3-didodecyloxypropyl) hydroxyethyl] ammonium bromide (DC) and DOPE (Figure 3B) could improve transfection into tumor cells expressing the CD44 receptor [36-39]. Furthermore, DOTAP/DOPE liposomes modified with HA-DOPE conjugate (Figure 3B) also exhibited improved stability in cell culture medium and a reduced cytotoxicity [40].

HA-PEI conjugates can form complexes with siRNA, miRNA, or pDNA by electrostatic interaction between negatively charged nucleic acids and the positively charged PEI moiety of the HA-PEI conjugate (Figure 5B) [41-47]. HA-PEI conjugates formed via an amide bond between the carboxyl groups of HA and the amine groups of branched PEI showed specific gene silencing efficacy by the addition of siRNA/HA-PEI polyplexes into tumor cells [42]. Han et al. also reported that HA-PEI could efficiently deliver siRNAs and antisense oligonucleotides (ODNs) into tumor cells with low cytotoxicity [45]. Furthermore, Park et al. reported that reducible HA-SS-PEI conjugate could be prepared with PEI cross-linked with cystamine bisacrylamide (PEI-SS), and intratumoral injection of vascular endothelial growth factor (VEGF) siRNA/HA-SS-PEI polyplexes (Figure $5 \mathrm{~B}$ ) resulted in dramatic inhibition of tumor growth with reduced VEGF mRNA and VEGF levels in the tumor [43]. HA-PEI conjugates have also been used for the delivery of pDNA into CD44-overexpressing macrophages [46].

Calcium phosphate, a natural inorganic material, has been regarded as a promising vehicle for gene delivery due to its biocompatibility, biodegradability, and ability to encapsulate negatively charged nucleic acids by chelating calcium ions. Lee et al. reported that calcium phosphate nanoparticles of siRNAs stabilized by inclusion of conjugates of 3,4-dihydroxy-L-phenylalanine (DOPA) and HA improved accumulation of the siRNA in tumors and induced high silencing effect of target gene after systemic administration [48]. 
HA can be directly conjugated to siRNAs [49] or antisense ODNs [50] via a reducible disulfide linkage. HA-SS-siRNA conjugate/PEI polyplexes (Figure 5C) exhibited improved stability against serum proteins, and silenced target gene expression via CD44-mediated endocytosis [49]. Moreover, HA-SS-antisense ODN conjugate/ protamine polyplexes (Figure 5C) increased cellular uptake and enhanced gene inhibition efficacy [50]. From these findings, the incorporation of HA into carrier systems may be useful for the delivery of therapeutic genes into CD44-overexpressing cells.

\section{Polyplexes or lipoplexes modified with chondroitin sulfate}

Glycosaminoglycans, including CS, attached to proteoglycans on the surface of tumor cells play key roles in malignant transformation and metastasis [51]. CS is an anionic linear polysaccharide, which consists of alternating disaccharide units of $\beta$-glucuronic acid-(1-3)- $N$-acetyl- $\beta$-galactosamine-6-sulfate (Figure 1), and it can bind to CD44. CS is currently applied as a symptomatic slow-acting drug for osteoarthritis (SYSADOA) agent in the treatment of osteoarthritis (OA) [52]. Uchida et al. reported that the addition of CS to pDNA/poly(ethylene glycol) (PEG)-block-poly $N$-[N-(2-aminoethyl)2-aminoethyl] aspartamide (PEG-PAsp(DET)) polyplexes markedly reduced damage of cellular membrane after in vitro and in vivo gene transfections [53]. We also found that CS attenuated inflammatory responses and hepatic toxicity induced by injection of DOTAP/Chol lipoplexes [54,55]. Therefore, CS may be a valuable material for the safe gene delivery (Table 2).

Lo et al. reported that CS-modified PEI/pDNA (Figure 5B) had a transfection efficiency similar to Lipofectamine lipoplexes of pDNA via clathrin-dependent and CD44-mediated endocytosis [56]. In addition, CS-modified PEI/microRNA-34a (miR34a) polyplexes and CS-modified PAMAM dendrimer/miR-34a polyplexes (Figure 5B) also showed significant inhibition of tumor growth and induction of tumor apoptosis via CD44-mediated endocytosis [57,58]. Kurosaki et al. reported that ternary complexes of encapsulated poly-L-arginine or poly-L-lysine polyplexes (Figure 5A) and DOTMA/Chol or DOTMA/DOPE lipoplexes of pDNA (Figure 3A) with CS showed high transgene expression in B16-F10 cells with low cytotoxicity and low agglutination with erythrocytes [59]. Furthermore, Hagiwara et al. reported that a ternary complex of pDNA/chitosan/CS (Figure 5A) exhibited high cellular uptake via micropinocytosis [60], and strongly inhibited tumor growth in Huh-7 tumor xenografts by intratumoral injection of the complexes with pDNA encoding herpes simplex virus thymidine kinase (HSV-tk) [61]. Hamada et al. reported that intraperitoneal injection of ternary complex (Figure 5A) of pDNA/PEI/CS encoding murine granulocyte macrophage-colony-

Table 2: Polyplexes or lipoplexes with chondroitin sulfate (CS) or CS conjugate for gene delivery.

\begin{tabular}{|c|c|c|c|}
\hline Nucleic acid & CS or CS Conjugate & Cationic polymer or liposome & Reference \\
\hline pDNA & CS & $\begin{array}{l}\text { DOTMA/Chol liposome } \\
\text { DOTMA/DOPE liposome } \\
\text { Poly-L-arginine } \\
\text { Poly-L-lysine }\end{array}$ & [59] \\
\hline pDNA & CS & Dendrigraft poly-L-lysine & [63] \\
\hline pDNA & CS & DOTAP/Chol liposome & [54] \\
\hline pDNA & CS & PEG-PAsp(DET) & [53] \\
\hline pDNA & CS & PEI & {$[62,65]$} \\
\hline pDNA & CS & PAMAM dendrimer & [64] \\
\hline pDNA & CS & Chitosan & {$[60,61]$} \\
\hline pDNA & CS-PEI & - & [56] \\
\hline miRNA & CS-PEI & - & [57] \\
\hline miRNA & CS-PAMAM & - & [58] \\
\hline
\end{tabular}

pDNA: plasmid DNA, miRNA: microRNA, CS: chondroitin sulfate, DOTMA: 1,2-di-O-octadecenyl-3-trimethylammonium propane, DOPE: 1,2-dioleoyl-sn-glycero-3-phosphoethanolamine, Chol: cholesterol, PEG-PAsp(DET): poly(ethylene glycol) (PEG)-block-poly \{N-[N-(2-aminoethyl)-2-aminoethyl]aspartamide\}. PEl: polyethylenimine, PAMAM: poly (amido amine). 
stimulating factor (mGM-CSF) prolonged survival in an intraperitoneal ovarian tumor model [62]. In addition, intratumoral injection of the ternary complex achieved mouse survival rates of $100 \%$ in a subcutaneous tumor model. From these findings, CS may be a useful polysaccharide for enhancing tumor transfection abilities in vitro and in vivo.

Kurosaki etal. reported that ternary complexes of pDNA/poly-L-lysine/CS or pDNA/ poly-L-arginine/CS (Figure 5A) led to high transgene expression in the spleen after intravenous injection [59]. They speculated that CS capsulation of pDNA polyplexes might be mainly recognized by macrophages in the spleen as a polysaccharide. Iwanaga et al. also reported that intravenous administration of ternary complexes of pDNA/ dendrigraft poly-L-lysine/CS (Figure 5A) induced high gene expression levels in the reticuloendothelial system [63]. Furthermore, Imamura et al. reported that a ternary complex of pDNA electrostatically assembled with PAMAM dendrimer and CS (Figure $5 \mathrm{~A})$ was an effective and secure gene vector, and they led to significantly higher gene expression in the spleen than pDNA/PAMAM dendrimer polyplexes [64]. Therefore, CS coating of polyplexes may be expected to be useful for gene vectors to the spleen, and they may be a promising approach for DNA vaccination. In addition, intravitreous administration of ternary complexes of pDNA/PEI/CS (Figure 5A) showed high gene expression in the retina, indicated that their complex are suitable for effective and safe ocular gene therapy [65].

\section{Polyplexes or lipoplexes modified with polyglutamic acid or heparin}

Poly- $\alpha$-glutamic acid $(\alpha \mathrm{PGA})$ is a synthetic polyamino acid with one $\mathrm{COOH}$ per glutamic acid unit (Figure 1). In contrast, poly- $\gamma$-glutamic acid ( $\gamma$-PGA) is a fermentation product made by Bacillus subtilis and is a polyamino acid connected through amide linkages between $\alpha$-amino and $\gamma$-carboxylic acid groups (Figure 1). A coating of PGA on cationic lipoplexes or polyplexes has the potential to improve delivery to tumor tissues while protecting normal tissue from toxic side effects (Table 3). Liao et al. reported that a $\gamma \mathrm{PGA}$ coating on pDNA/chitosan polyplexes (Figure $5 \mathrm{~A}$ ) significantly enhanced their cellular uptake via a specific $\gamma$-glutamyl transpeptidase (GGT) [66,67]. GGT is a cell surface enzyme that catalyzes amide hydrolysis of the $\gamma$-glutamyl group of glutathione in cells [68]. The amine group in the N-terminal $\gamma$-glutamyl unit on $\gamma$-PGA played an essential role in the interaction with GGT. GGT is overexpressed in several human cancers [69-72]. Therefore, $\gamma \mathrm{PGA}$ is used for targeting to tumor cells that overexpressed GGT on the cell surface.

Liao et al. reported that the inclusion of $\gamma \mathrm{PGA}$ did not alter the complex-formation ability between siRNA and chitosan, but it significantly increased cellular uptake and gene silencing effects [73]. Kodama et al. demonstrated that intratumoral injection of

Table 3: Polyplexes or lipoplexes with polyglutamic acid, heparin, alginic acid, or pectin for gene delivery.

\begin{tabular}{|c|c|c|c|}
\hline Nucleic acid & Anionic polymer or its conjugate & Cationic polymer or liposome & Reference \\
\hline pDNA & rPGA & Chitosan & {$[66,67]$} \\
\hline pDNA & rPGA & Dendrigraft poly-L-lysine & {$[80]$} \\
\hline pDNA & rPGA & PEI & {$[81-83]$} \\
\hline pDNA & rPGA & Protamine & {$[75]$} \\
\hline pDNA & aPGA & DOTAP/Chol liposome & {$[54]$} \\
\hline siRNA & rPGA & Chitosan & {$[73]$} \\
\hline siRNA & rPGA & Dendrigraft poly-L-lysine & {$[74]$} \\
\hline siRNA & aPGA & DOTAP/Chol liposome & {$[78,79]$} \\
\hline siRNA & aPGA & DMAPAP/DOPE liposome & {$[76]$} \\
\hline siRNA & rPGA & PEl & {$[84]$} \\
\hline pDNA & Heparin & Cationic glycopolymer $($ Tr4) & {$[85]$} \\
\hline pDNA & Heparin-PEI & - & {$[24]$} \\
\hline pDNA & Alginic acid, Pectin & Lipofectamine 2000 & \\
\hline
\end{tabular}

pDNA: plasmid DNA, siRNA: small interfering RNA, rPGA: poly-r-glutamic acid, aPGA: poly-a-glutamic acid, PEl: polyethylenimine, DMAPAP: 2-\{3-[bis-(3-amino-propyl)-amino]-propylamino\}- $N$-ditetradecyl carbamoyl methylacetamide, Chol: cholesterol, DOPE: 1,2-dioleoyl-sn-glycero-3-phosphoethanolamine. 
a ternary complex of siRNA/dendrigraft poly-L-lysine $/ \gamma \mathrm{PGA}$ (Figure $5 \mathrm{~A}$ ) suppressed the expression of the target gene in Colon 26 tumor-bearing mice [74]. Moreover, a ternary complex of pDNA/protamine/ $\gamma$ PGA (Figure $5 \mathrm{~A}$ ) was taken up by clathrinmediated endocytosis and macropinosytosis and showed high transfection efficiency in B16-F10 cells [75]. In addition, a ternary complex of siRNA/PEI/ $\gamma$ PGA (Figure 5A) showed a high gene silencing effect and no cytotoxicity in B16-F10 cells [76]. From these findings, ternary complexes with $\gamma \mathrm{PGA}$ may be a potential carrier for targeting tumor cells.

$\alpha$ PGA coating of DOTAP/Chol lipoplex of siRNA or pDNA (Figure 3A) increased accumulation of the lipoplex in the liver after intravenous injection [54,77]. In addition, $\alpha$ PGA coating of 2-\{3-[bis-(3-amino-propyl)-amino]-propylamino- $\mathrm{N}$ ditetradecyl carbamoyl methyl-acetamide (DMAPAP)/DOPE lipoplexes of siRNA (Figure 3A) decreased in vitro and in vivo toxicities and enhanced siRNA delivery to the liver and lung after systemic injection $[78,79]$. Intravenous injection of $\gamma \mathrm{PGA}$ is mainly accumulated in the spleen and liver in mice. Kodama et al. reported that a ternary complex of pDNA/dendrigraft poly-L-lysine/ $\gamma$ PGA (Figure 5A) displayed high transfection efficiency only in the spleen, although pDNA/dendrigraft poly-L-lysine polyplexes induced high transfection efficiency in the liver, lungs, and spleen [80]. Furthermore, a ternary complex of pDNA/PEI/ $\gamma$ PGA (Figure 5A) was taken up by a $\gamma$ PGA-specific receptor-mediated energy dependent process [81], and they showed high transgene expression in the spleen without toxicity $[82,83]$. Therefore, $\gamma$ PGA coating of polyplexes may be also useful for safe gene vector to the spleen.

Heparin is a biocompatible, nontoxic glycosaminoglycan that is used clinically as an anticoagulant to treat venous thrombosis or to prevent thrombosis. Heparin has repeating disaccharide units consisting of uronic acid (L-iduronic or D-glucuronic acid) linked $1 \rightarrow 4$ to D-glucosamine (Figure 1). Boyle et al. reported that the addition of low doses of heparin can significantly increase pDNA delivery by a cationic glycopolymer (Tr4) (Figure 5A) [84]. They speculated that heparin coating of the polyplexes appeared to improve cell surface binding, internalization, intracellular trafficking of polyplexes to the nucleus, leading to high transgene expression. Furthermore, chemically conjugated PEI with heparin (heparin-PEI) formed a nanogel, and intravenous injection of heparin-PEI and pDNA complexes (Figure 5B) exhibited high distribution of pDNA in the lung, and inhibited lung metastasis of malignant melanoma B16-F10 and mouse colon carcinoma Colon 26 by injection of pDNA encoding interleukin 15 gene [85], indicated that the heparin-PEI conjugate is an efficient gene carrier to the lung.

\section{Sequential injection of anionic polymer and siRNA lipoplexes}

$\alpha$ PGA or CS coating of DOTAP/Chol lipoplexes with siRNAs or pDNAs prevented aggregation with erythrocytes, and increased accumulation of lipoplexes in the liver after intravenous injection (Figure 6A,B) [54,77]. Recently, we revisited the gene transfer method with anionic polymer-coated ternary complexes, because in the coating of cationic lipoplexes with the anionic polymer, the size and $\zeta$-potential of the ternary complexes were largely affected by changing the charge ratio (+/-) of cationic lipoplexes to anionic polymer; therefore, this charge ratio (+/-) must be exactly controlled for preparation of anionic polymer-coating lipoplexes before intravenous injection [54,77]. In addition, anionic polymers caused dissociation of siRNA from siRNA lipoplexes by competition for binding to cationic liposomes before intravenous injection [77]. Therefore, we developed a sequential injection method that cationic lipoplexes with siRNA were injected intravenously soon after intravenous injection of anionic polymer. For example, intravenous injection of DOTAP/Chol lipoplexes induced large accumulation in the lungs (Figure 6A and 7); however, intravenous injection of $1 \mathrm{mg} C \mathrm{CS}$ or $\alpha$ PGA into mice, followed by intravenous injection of DOTAP/Chol lipoplexes at a 1 min interval delivered siRNA to the liver efficiently without accumulation in the lungs 
(Figure 6C and 7) [86,87]. This method has an advantage of not requiring preparation of ternary complexes, which is sometimes unstable in solution, by neutralizing the surface charge of the lipoplexes. Regarding the liposomal formulation, cationic liposomes composed of DOTAP/DOPE, DOTMA/Chol, dimethyldioctade-cylammonium bromide (DDAB)/Chol and $O, O^{\prime}$-ditetradecanoyl- $N$ - $(\alpha$-trimethylammonioacetyl) diethanolamine chloride (DC-6-14)/Chol could also efficiently deliver siRNAs into the liver by sequential injection with $\alpha \mathrm{PGA}$ [87]. Moreover, intramuscular, intraperitoneal, or subcutaneous injection of CS into mice before intravenous injection of DOTAP/Chol lipoplexes also resulted in siRNA accumulation mainly in the liver [88]. We found that regardless of the injection route of $\mathrm{CS}$, the concentration of $\mathrm{CS}$ in serum needed to

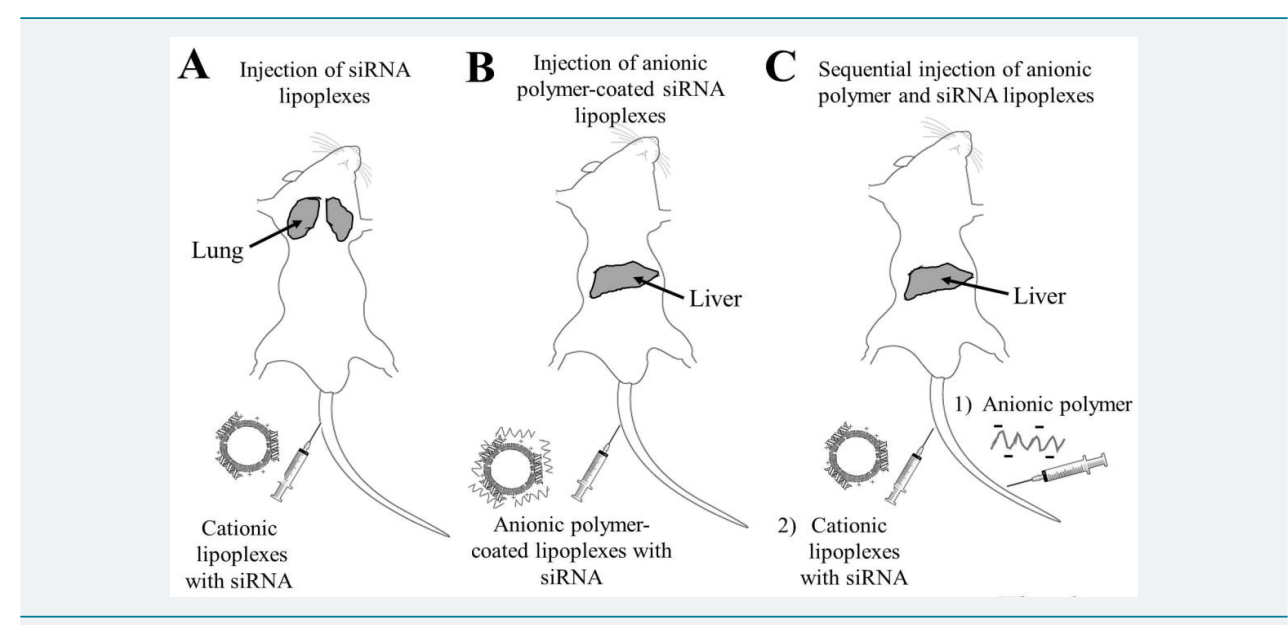

Figure 6: Biodistribution of small interfering RNAs (siRNAs) in mice after intravenous injection of siRNA lipoplexes (A), intravenous injection of anionic polymer-coated siRNA lipoplexes (B), and intravenous injection of anionic polymer, followed by injection of siRNA lipoplexes (C). Gray areas indicate organs where siRNA accumulated.

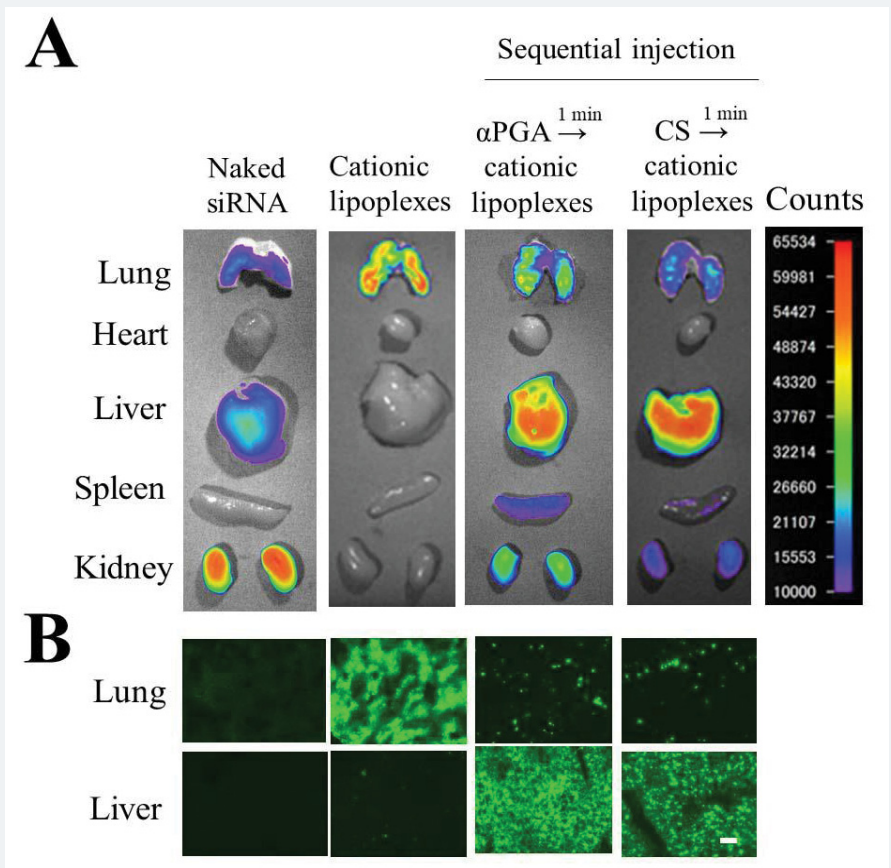

Figure 7: Effect of chondroitin sulfate (CS) or poly-a-glutamic acid (aPGA) on the biodistribution of small interfering RNAs (siRNAs) in mice after intravenous injection of DOTAP/Chol lipoplexes [86-88]. In sequential injection, at 1 min after intravenous injection of $1 \mathrm{mg}$ CS or aPGA, DOTAP/Chol lipoplexes with Cy5.5-labeled siRNA (Cy5.5-siRNA) were administered intravenously to mice [86-88]. Ex vivo images of dissected tissues $(A)$ and tissue sections (lung and liver) (B) were obtained at $1 \mathrm{~h}$ after injection of siRNA lipoplexes. In A, fluorescence intensity is illustrated using a color-coded scale (red is maximum, purple is minimum). In B, green signals indicate the localization of Cy5.5siRNA. Scale bar $=100 \mu \mathrm{m}$. 
be above $20 \mu \mathrm{g} / \mathrm{mL}$ for efficient siRNA delivery to the liver after sequential injection [88]. We speculated that CS or $\alpha$ PGA injection might prevent the agglutination of siRNA lipoplexes with erythrocytes by the interaction of siRNA lipoplexes with CS or $\alpha$ PGA in the blood circulation and increased accumulation in the liver. In terms of gene silencing effect, siRNAs delivered by this sequential injection with $\alpha$ PGA or CS could significantly suppress mRNA expression of the target gene in the liver or liver metastasis $[55,86]$. Regarding the side effects, sequential injection of $\alpha$ PGA plus siRNA lipoplexes exhibited hepatic damage and resulted in the induction of inflammatory cytokines such as TNF $\alpha$ and interleukin-10 in serum, but sequential injection of CS plus siRNA lipoplexes did not [55]. CS is a compound with an anti-inflammatory activity and available for the treatment of OA patients [52]. CS attenuates inflammatory responses in macrophages via the suppression of NF-kB nuclear translocation $[89,90]$. Therefore, CS might be able to suppress the inflammatory responses induced by the injection of cationic lipoplexes. In addition, sequential injections of CS plus cationic lipoplexes with protein kinase N3 (PKN3) siRNA could suppress tumor growth in the mice bearing liver metastasis of human breast tumor MCF-7 or MDA-MB-231 [55,91]. From these findings, sequential injection of CS and siRNA lipoplexes might be a novel systemic method of delivering siRNA to liver and liver metastasis.

\section{CONCLUSION}

Recently, gene therapy with non-viral vector is making excellent progress. For clinical gene therapy, not only high transfection efficiency but also biocompatibility for frequent dosing is indispensable. It is notable that although HA, CS, and PGA encapsulation or modification for lipoplexes or polyplexes did not reduce the transfection efficiency, they markedly decreased side effects such as hepatotoxicity, indicating their utility in clinical gene delivery systems. In addition, sequential injection of CS plus cationic lipoplexes was capable of delivering siRNAs into the liver and tumor-metastasized liver without hepatotoxicity or the induction of inflammatory cytokines. From these findings, the methods of gene delivery by polyplexes or lipoplexes with anionic polymers may be an outstanding tool for delivering nucleic acid-based therapeutics into targeted tissues or tumors. In more advanced gene therapy, the polyplexes or lipoplexes with anionic polymers are required to deliver nucleic acid-based therapeutics into specific cells of targeted tissue. Anionic polymer can be chemically conjugated with ligand having affinity to receptor on cell surface (for example, conjugate of folic acid and chondroitin sulfate for targeting tumor cells via folate receptor). Along with shielding the positive charge of cationic complexes by anionic polymer, targeting delivery to specific cells via the receptor on cell surface will be accomplished by ligands conjugated to anionic polymer.

\section{ACKNOWLEDGEMENT}

This project was supported in part by a Grant-in-Aid for Scientific Research (C) from the Japan Society for the Promotion of Science (KAKENHI Grant Number JP26460046 and JP17K08251).

\section{REFERENCES}

1. Collins M, Thrasher AA. Gene therapy: progress and predictions. Proc Biol Sci. 2015; 282. Ref.: https://goo.gl/MpvdAg

2. Aagaard L, Rossi JJ. RNAi therapeutics: principles, prospects and challenges. Adv Drug Deliv Rev. 2007; 59: 75-86. Ref.: https://goo.gl/w6Ljep

3. He L, Hannon GJ. MicroRNAs: small RNAs with a big role in gene regulation. Nat Rev Genet. 2004; 5 : 522-531. Ref.: https://goo.gl/xtPsZE

4. Wang $H$, Jiang $Y$, Peng $H$, Chen $Y$, Zhu $P$, et al. Recent progress in microRNA delivery for cancer therapy by non-viral synthetic vectors. Adv Drug Deliv Rev. 2015; 81: 142-160. Ref.: https://goo.gl/pr7ZdH 
5. Zhang Y, Wang Z, Gemeinhart RA. Progress in microRNA delivery. J Control Release. 2013; 172: 962974. Ref.: https://goo.gl/ZFRb69

6. Roberts TC, Ezzat K, El Andaloussi S, Weinberg MS. Synthetic SiRNA Delivery: Progress and Prospects. Methods Mol Biol. 2016; 1364: 291-310. Ref.: https://goo.gl/WDZAmf

7. Young LS, Searle PF, Onion D, Mautner V. Viral gene therapy strategies: from basic science to clinical application. J Pathol. 2006; 208: 299-318. Ref.: https://goo.gl/uvg8Ay

8. Kaiser J. Gene therapy. Seeking the cause of induced leukemias in X-SCID trial. Science. 2003; 299 : 495. Ref.: https://goo.gl/nsHKvE

9. Yin $\mathrm{H}$, Kanasty RL, Eltoukhy AA, Vegas AJ, Dorkin JR, et al. Non-viral vectors for gene-based therapy Nat Rev Genet. 2014; 15: 541-555. Ref.: https://goo.gl/zRNE5K

10. Glover DJ, Lipps HJ, Jans DA. Towards safe, non-viral therapeutic gene expression in humans. Nat Rev Genet. 2005; 6: 299-310. Ref.: https://goo.gl/Dp8a7i

11. Zhou J, Shum KT, Burnett JC, Rossi JJ. Nanoparticle-Based Delivery of RNAi Therapeutics: Progress and Challenges. Pharmaceuticals. 2013; 6: 85-107. Ref.: https://goo.gl/eXwyQM

12. Zhang S, Zhi D, Huang L. Lipid-based vectors for siRNA delivery. J Drug Target. 2012; 20: 724-735. Ref.: https://goo.gl/QjH3mf

13. Hwang SJ, Davis ME. Cationic polymers for gene delivery: designs for overcoming barriers to systemic administration. Curr Opin Mol Ther. 2001; 3: 183-191. Ref.: https://goo.gl/QXaq9z

14. Goula D, Benoist C, Mantero S, Merlo G, Levi G, et al. Polyethylenimine-based intravenous delivery of transgenes to mouse lung. Gene Ther. 1998; 5: 1291-1295. Ref.: https://goo.gl/4Jkmpk

15. Yeeprae W, Kawakami S, Suzuki S, Yamashita F, Hashida M. Physicochemical and pharmacokinetic characteristics of cationic liposomes. Pharmazie. 2006; 61: 102-105. Ref.: https://goo.gl/bFxs41

16. Eliyahu H, Servel N, Domb AJ, Barenholz Y. Lipoplex-induced hemagglutination: potential involvement in intravenous gene delivery. Gene Ther. 2002; 9: 850-858. Ref.: https://goo.gl/npqi3U

17. Simberg D, Weisman S, Talmon Y, Faerman A, Shoshani T, et al. The role of organ vascularization and lipoplex-serum initial contact in intravenous murine lipofection. J Biol Chem. 2003; 278: 3985839865. Ref.: https://goo.gl/W8gqip

18. Hattori Y. Delivery of plasmid DNA into tumors by intravenous injection of PEGylated cationic lipoplexes into tumor-bearing mice. Pharmacology \& Pharmacy. 2016; 7.

19. Gjetting T, Arildsen NS, Christensen CL, Poulsen TT, Roth JA, et al. In vitro and in vivo effects of polyethylene glycol (PEG)-modified lipid in DOTAP/cholesterol-mediated gene transfection. Int $J$ Nanomedicine. 2010; 5: 371-383. Ref.: https://goo.gl/wLcjFt

20. Bourguignon LY. Hyaluronan-mediated CD44 activation of RhoGTPase signaling and cytoskeleton function promotes tumor progression. Semin Cancer Biol. 2008; 18: 251-259. Ref.: https://goo.gl/9xxva6

21. Cortes-Dericks L, Schmid RA. CD44 and its ligand hyaluronan as potential biomarkers in malignant pleural mesothelioma: evidence and perspectives. Respir Res. 2017; 18: 58. Ref.: https://goo.gl/6SvFda

22. Toole BP. Hyaluronan-CD44 Interactions in Cancer: Paradoxes and Possibilities. Clin Cancer Res. 2009; 15: 7462-7468. Ref.: https://goo.gl/pcCFMU

23. Xie F, Zhang L, Peng J, Li C, Pu J, et al. Hepatic Carcinoma Selective Nucleic Acid Nanovector Assembled by Endogenous Molecules Based on Modular Strategy. Mol Pharm. 2017; 14: 1841-1851. Ref.: https://goo.gl/td4jGT

24. Chen M, Zeng Z, Qu X, Tang Y, Long Q, et al. Biocompatible anionic polyelectrolyte for improved liposome based gene transfection. Int J Pharm. 2015; 490: 173-179. Ref.: https://goo.gl/bHhj68

25. Lu HD, Zhao HQ, Wang K, Lv LL. Novel hyaluronic acid-chitosan nanoparticles as non-viral gene delivery vectors targeting osteoarthritis. Int J Pharm. 2011; 420: 358-365. Ref.: https://goo.gl/ynnqri

26. Lu H, Lv L, Dai Y, Wu G, Zhao H, et al. Porous chitosan scaffolds with embedded hyaluronic acid/ chitosan/plasmid-DNA nanoparticles encoding TGF- $\beta 1$ induce DNA controlled release, transfected chondrocytes, and promoted cell proliferation. PloS one. 2013; 8. Ref.: https://goo.gl/rpgcwQ

27. Raviña M, Cubillo E, Olmeda D, Novoa-Carballal R, Fernandez-Megia E, et al. Hyaluronic acid/chitosang-poly(ethylene glycol) nanoparticles for gene therapy: an application for pDNA and siRNA delivery. Pharm Res. 2010; 27: 2544-2555. Ref.: https://goo.gl/JMcnXV 
28. Ito T, Koyama Y, Otsuka M. Analysis of the surface structure of DNA/polycation/hyaluronic acid ternary complex by Raman microscopy. J Pharm Biomed Anal. 2010; 51: 268-272. Ref.: https://goo.gl/8TTMxc

29. Ito T, Koyama Y, Otsuka M. Preparation of calcium phosphate nanocapsule including deoxyribonucleic acid-polyethyleneimine-hyaluronic acid ternary complex for durable gene delivery. J Pharm Sci. 2014; 103: 179-184. Ref.: https://goo.gl/tevmrh

30. Koyama Y, Sugiura K, Yoshihara C, Inaba T, Ito T. Highly Effective Non-Viral Antitumor Gene Therapy System Comprised of Biocompatible Small Plasmid Complex Particles Consisting of pDNA, Anionic Polysaccharide, and Fully Deprotected Linear Polyethylenimine. Pharmaceutics. 2015; 7: 152-164. Ref.: https://goo.gl/J2CNsp

31. Li Y, Zhang J, Wang B, Shen Y, Ouahab A. Co-delivery of siRNA and hypericin into cancer cells by hyaluronic acid modified PLGA-PEI nanoparticles. Drug Dev Ind Pharm. 2016; 42: 737-746. Ref.: https://goo.gl/T1JGhu

32. Zhao MD, Cheng JL, Yan JJ, Chen FY, Sheng JZ, et al. Hyaluronic acid reagent functional chitosanPEI conjugate with AQP2-siRNA suppressed endometriotic lesion formation. Int $\mathrm{J}$ Nanomedicine. 2016; 11: 1323-1336. Ref.: https://goo.gl/5LQk7N

33. Chen CJ, Zhao ZX, Wang JC, Zhao EY, Gao LY, et al. A comparative study of three ternary complexes prepared in different mixing orders of siRNA/redox-responsive hyperbranched poly (amido amine)/ hyaluronic acid. Int J Nanomedicine. 2012; 7: 3837-3849. Ref.: https://goo.gl/FEtQ2n

34. Gu J, Chen X, Ren X, Zhang X, Fang X, et al. CD44-Targeted Hyaluronic Acid-Coated RedoxResponsive Hyperbranched Poly(amido amine)/Plasmid DNA Ternary Nanoassemblies for Efficient Gene Delivery. Bioconjug Chem. 2016; 27: 1723-1736. Ref.: https://goo.gl/WA48jv

35. Kim EJ, Shim G, Kim K, Kwon IC, Oh YK, et al. Hyaluronic acid complexed to biodegradable poly L-arginine for targeted delivery of siRNAs. The J Gene Med. 2009; 11: 791-803. Ref.: https://goo.gl/2cmfJb

36. Surace C, Arpicco S, Dufaÿ-Wojcicki A, Marsaud V, Bouclier C, et al. Lipoplexes targeting the CD44 hyaluronic acid receptor for efficient transfection of breast cancer cells. Mol Pharm. 2009; 6: 10621073. Ref.: https://goo.gl/rTUoFA

37. Dufaÿ Wojcicki A, Hillaireau H, Nascimento TL, Arpicco S, Taverna M, et al. Hyaluronic acid-bearing lipoplexes: physico-chemical characterization and in vitro targeting of the CD44 receptor. J Control Release. 2012; 162: 545-552. Ref.: https://goo.gl/DEP7mL

38. Leite Nascimento T, Hillaireau $H$, Vergnaud J, Rivano $M$, Deloménie $C$, et al. Hyaluronic acidconjugated lipoplexes for targeted delivery of siRNA in a murine metastatic lung cancer model. Int $J$ Pharm. 2016; 514: 103-111. Ref.: https://goo.gl/Ztr3q5

39. Nascimento TL, Hillaireau $H$, Noiray M, Bourgaux C, Arpicco S, et al. Supramolecular Organization and siRNA Binding of Hyaluronic Acid-Coated Lipoplexes for Targeted Delivery to the CD44 Receptor Langmuir. 2015; 31: 11186-11194. Ref.: https://goo.gl/QwyYoY

40. Taetz S, Bochot A, Surace C, Arpicco S, Renoir JM, et al. Hyaluronic acid-modified DOTAP/DOPE liposomes for the targeted delivery of anti-telomerase siRNA to CD44-expressing lung cancer cells. Oligonucleotides. 2009; 19: 103-116. Ref.: https://goo.gl/4XksiJ

41. Yang X, lyer AK, Singh A, Milane L, Choy E, et al. Cluster of Differentiation 44 Targeted Hyaluronic Acid Based Nanoparticles for MDR1 siRNA Delivery to Overcome Drug Resistance in Ovarian Cancer. Pharm Res. 2015; 32: 2097-2109. Ref.: https://goo.gl/Vamt93

42. Jiang G, Park K, Kim J, Kim KS, Oh EJ, et al. Hyaluronic acid-polyethyleneimine conjugate for target specific intracellular delivery of siRNA. Biopolymers. 2008; 89: 635-642. Ref.: https://goo.gl/D7PuEF

43. Park K, Lee MY, Kim KS, Hahn SK. Target specific tumor treatment by VEGF siRNA complexed with reducible polyethyleneimine-hyaluronic acid conjugate. Biomaterials. 2010; 31: 5258-5265. Ref.: https://goo.gl/GwUTLX

44. Ganesh S, lyer AK, Morrissey DV, Amiji MM. Hyaluronic acid based self-assembling nanosystems for CD44 target mediated siRNA delivery to solid tumors. Biomaterials. 2013; 34: 3489-3502. Ref.: https://goo.gl/5NYVTw

45. Han SE, Kang H, Shim GY, Kim SJ, Choi HG, et al. Cationic derivatives of biocompatible hyaluronic acids for delivery of siRNA and antisense oligonucleotides. J Drug Target. 2009; 17: 123-132. Ref.: https://goo.gl/FysFvE

46. Tran TH, Rastogi R, Shelke J, Amiji MM. Modulation of Macrophage Functional Polarity towards Anti-Inflammatory Phenotype with Plasmid DNA Delivery in CD44 Targeting Hyaluronic Acid Nanoparticles. Sci Rep. 2015; 5: 16632. Ref.: https://goo.gl/DXrNH8 
47. Tran TH, Krishnan S, Amiji MM. MicroRNA-223 Induced Repolarization of Peritoneal Macrophages Using CD44 Targeting Hyaluronic Acid Nanoparticles for Anti-Inflammatory Effects. PloS one. 2016; 11. Ref.: https://goo.gl/yujGhm

48. Lee MS, Lee JE, Byun E, Kim NW, Lee K, et al. Target-specific delivery of siRNA by stabilized calcium phosphate nanoparticles using dopa-hyaluronic acid conjugate. J Control Release. 2014; 192: 122130. Ref.: https://goo.gl/9BdWDp

49. Jang $\mathrm{YL}$, Ku SH, Jin S, Park JH, Kim WJ, et al. Hyaluronic acid-siRNA conjugate/reducible polyethylenimine complexes for targeted siRNA delivery. J Nanosci Nanotechnol. 2014; 14: 73887394. Ref.: https://goo.gl/yQ7KsP

50. Mok H, Park JW, Park TG. Antisense oligodeoxynucleotide-conjugated hyaluronic acid/protamine nanocomplexes for intracellular gene inhibition. Bioconjug Chem. 2007; 18: 1483-1489. Ref.: https://goo.gl/AqgFzn

51. Mizumoto S, Sugahara K. Glycosaminoglycans are functional ligands for receptor for advanced glycation end-products in tumors. FEBS J. 2013; 280: 2462-2470. Ref.: https://goo.gl/6WXTEh

52. Henrotin $Y$, Mathy M, Sanchez C, Lambert C. Chondroitin sulfate in the treatment of osteoarthritis: from in vitro studies to clinical recommendations. Ther Adv Musculoskelet Dis. 2010; 2: 335-348. Ref.: https://goo.gl/bN4A1J

53. Uchida S, Itaka K, Chen Q, Osada K, Miyata K, et al. T. Combination of chondroitin sulfate and polyplex micelles from Poly(ethylene glycol)-poly\{ $\mathrm{N}^{\prime}$-[N-(2-aminoethyl)-2-aminoethyl]aspartamide block copolymer for prolonged in vivo gene transfection with reduced toxicity. J Control Release. 2011; 155: 296-302.

54. Hattori $Y$, Yamasaku H, Maitani Y. Anionic polymer-coated lipoplex for safe gene delivery into tumor by systemic injection. J Drug Target. 2013; 21: 639-647. Ref.: https://goo.gl/YnRp23

55. Hattori Y, Arai S, Kikuchi T, Ozaki KI, Kawano K, et al. Therapeutic effect for liver-metastasized tumor by sequential intravenous injection of anionic polymer and cationic lipoplex of siRNA. J Drug Target. 2016; 24: 309-317. Ref.: https://goo.gl/HaoJZ1

56. Lo YL, Sung KH, Chiu CC, Wang LF. Chemically conjugating polyethylenimine with chondroitin sulfate to promote CD44-mediated endocytosis for gene delivery. Mol Pharm. 2013; 10: 664-676. Ref.: https://goo.gl/hXHZmc

57. Liang S, Duan $Y$, Xing Z, Han H, Zhang A, et al. Inhibition of cell proliferation and migration by chondroitin sulfate-g-polyethylenimine-mediated miR-34a delivery. Colloids Surf B Biointerfaces. 2015; 136: 577-584. Ref.: https://goo.gl/VcoikX

58. Chen W, Liu Y, Liang X, Huang Y, Li Q. Chondroitin sulfate-functionalized polyamidoamine as a tumortargeted carrier for miR-34a delivery. Acta biomater. 2017; 57: 238-250. Ref.: https://goo.gl/2VpD2E

59. Kurosaki T, Kitahara T, Fumoto S, Nishida K, Yamamoto K, et al. Chondroitin sulfate capsule system for efficient and secure gene delivery. J Pharm Pharm Sci. 2010; 13: 351-361. Ref.: |https://goo.gl/36Rj1T

60. Hagiwara K, Nakata M, Koyama Y, Sato T. The effects of coating pDNA/chitosan complexes with chondroitin sulfate on physicochemical characteristics and cell transfection. Biomaterials. 2012; 33 7251-7260. Ref.: https://goo.gl/PTwfKF

61. Hagiwara K, Kishimoto S, Ishihara M, Koyama $\mathrm{Y}$, Mazda O, et al. In vivo gene transfer using pDNA/ chitosan/chondroitin sulfate ternary complexes: influence of chondroitin sulfate on the stability of freeze-dried complexes and transgene expression in vivo. J Gene Med. 2013; 15: 83-92. Ref.: https://goo.gl/Vbktx4

62. Hamada K, Yoshihara C, Ito T, Tani K, Tagawa M, et al. Antitumor effect of chondroitin sulfate-coated ternary granulocyte macrophage-colony-stimulating factor plasmid complex for ovarian cancer. $J$ Gene Med. 2012; 14: 120-127. Ref.: https://goo.gl/sc2j3a

63. Iwanaga $\mathrm{M}$, Kodama $\mathrm{Y}$, Muro $\mathrm{T}$, Nakagawa $\mathrm{H}$, Kurosaki $\mathrm{T}$, et al. Biocompatible complex coated with glycosaminoglycan for gene delivery. J Drug Target. 2017; 25: 370-378. Ref.: https://goo.gl/23rjZJ

64. Imamura M, Kodama Y, Higuchi N, Kanda K, Nakagawa $\mathrm{H}$, et al. Ternary complex of plasmid DNA electrostatically assembled with polyamidoamine dendrimer and chondroitin sulfate for effective and secure gene delivery. Biol Pharm Bull. 2014; 37: 552-559. Ref.: https://goo.gl/mrgDuM

65. Kurosaki T, Uematsu M, Shimoda K, Suzuma K, Nakai M, et al. Ocular gene delivery systems using ternary complexes of plasmid DNA, polyethylenimine, and anionic polymers. Biol Pharm Bull. 2013 36: 96-101. Ref.: https://goo.gl/asDxcu 
66. Liao ZX, Peng SF, Ho YC, Mi FL, Maiti B, et al. Mechanistic study of transfection of chitosan/DNA complexes coated by anionic poly(gamma-glutamic acid). Biomaterials. 2012; 33: 3306-3315. Ref.: https://goo.gl/4zW749

67. Peng SF, Tseng MT, Ho YC, Wei MC, Liao ZX, et al. Mechanisms of cellular uptake and intracellular trafficking with chitosan/DNA/poly(gamma-glutamic acid) complexes as a gene delivery vector. Biomaterials. 2011; 32: 239-248. Ref.: https://goo.gl/amcfS3

68. Hanigan $\mathrm{MH}$, Ricketts WA. Extracellular glutathione is a source of cysteine for cells that express gamma-glutamyl transpeptidase. Biochemistry. 1993; 32: 6302-6306. Ref.: https://goo.gl/cvbf71

69. Pompella A, De Tata V, Paolicchi A, Zunino F. Expression of gamma-glutamyltransferase in cancer cells and its significance in drug resistance. Biochem Pharmacol. 2006; 71: 231-238. Ref.: https://goo.gl/PXag69

70. Schafer C, Fels C, Brucke M, Holzhausen HJ, Bahn H, et al. Gamma-glutamyl transferase expression in higher-grade astrocytic glioma. Acta Oncol. 2001; 40: 529-535. Ref.: https://goo.gl/YneGs5

71. Yao D, Jiang D, Huang Z, Lu J, Tao Q, et al. Abnormal expression of hepatoma specific gammaglutamyl transferase and alteration of gamma-glutamyl transferase gene methylation status in patients with hepatocellular carcinoma. Cancer. 2000; 88: 761-769. Ref.: https://goo.gl/9AhhC2

72. Hanigan MH, Frierson HF Jr, Brown JE, Lovell MA, Taylor PT. Human ovarian tumors express gammaglutamyl transpeptidase. Cancer Res. 1994; 54: 286-290. Ref.: https://goo.gl/PWbnX5

73. Liao ZX, Ho YC, Chen HL, Peng SF, Hsiao CW, et al. Enhancement of efficiencies of the cellular uptake and gene silencing of chitosan/siRNA complexes via the inclusion of a negatively charged poly(gamma-glutamic acid). Biomaterials. 2010; 31: 8780-8788. Ref.: https://goo.gl/K4fK1H

74. Kodama $Y$, Kuramoto $\mathrm{H}$, Mieda $\mathrm{Y}$, Muro T, Nakagawa $\mathrm{H}$, et al. Application of biodegradable dendrigraft poly-l-lysine to a small interfering RNA delivery system. J Drug Target. 2017; 25: 49-57. Ref.: https://goo.gl/M7pyVt

75. Kanda K, Kodama Y, Kurosaki T, Imamura M, Nakagawa H, et al. Ternary complex of plasmid DNA with protamine and gamma-polyglutamic acid for biocompatible gene delivery system. Biol Pharm Bull. 2013; 36: 1794-1799. Ref.: https://goo.gl/bBRTNr

76. Kodama Y, Shiokawa Y, Nakamura T, Kurosaki T, Aki K, et al. Novel siRNA delivery system using a ternary polymer complex with strong silencing effect and no cytotoxicity. Biol Pharm Bull. 2014; 37: 1274-1281. Ref.: https://goo.gl/L61STv

77. Hattori $\mathrm{Y}$, Nakamura A, Arai S, Nishigaki M, Ohkura $\mathrm{H}$, et al. In vivo siRNA delivery system for targeting to the liver by poly-I-glutamic acid-coated lipoplex, Results Pharma Sci. 2014; 4: 1-7. Ref.: https://goo.gl/96eSUj

78. Schlegel A, Largeau C, Bigey P, Bessodes M, Lebozec K, et al. Anionic polymers for decreased toxicity and enhanced in vivo delivery of siRNA complexed with cationic liposomes. J Control Release. 2011 152: 393-401. Ref.: https://goo.gl/uQDVxW

79. Schlegel A, Bigey $P$, Dhotel H, Scherman D, Escriou V. Reduced in vitro and in vivo toxicity of siRNA-lipoplexes with addition of polyglutamate. J Control Release. 2013; 165: 1-8. Ref.: https://goo.gl/tZHkSo

80. Kodama Y, Nakamura T, Kurosaki T, Egashira K, Mine T, et al. Biodegradable nanoparticles composed of dendrigraft poly-L-lysine for gene delivery. Eur J Pharm Biopharm. 2014; 87: 472-479. Ref.: https://goo.gl/7ghqB4

81. Kurosaki T, Kitahara T, Fumoto S, Nishida K, Nakamura J, et al. Ternary complexes of pDNA polyethylenimine, and gamma-polyglutamic acid for gene delivery systems. Biomaterials. 2009; 30 2846-2853. Ref.: https://goo.gl/CEjceW

82. Kurosaki T, Kodama $\mathrm{Y}$, Muro T, Higuchi N, Nakamura T, et al. Secure splenic delivery of plasmid DNA and its application to DNA vaccine. Biol Pharm Bull. 2013; 36: 1800-1806. Ref.: https://goo.gl/sPQjwY

83. Tripathi SK, Goyal R, Ansari KM, Ravi Ram K, Shukla Y, et al. Polyglutamic acid-based nanocomposites as efficient non-viral gene carriers in vitro and in vivo. Eur J Pharm Biopharm. 2011; 79: 473-484. Ref.: https://goo.gl/9m2ySs

84. Boyle WS, Senger K, Tolar J, Reineke TM. Heparin Enhances Transfection in Concert with a Trehalose-Based Polycation with Challenging Cell Types. Biomacromolecules. 2017; 18: 56-67. Ref.: https://goo.gl/6PyzkG

85. Zhou X, Li X, Gou M, Qiu J, Li J,et al. Antitumoral efficacy by systemic delivery of heparin conjugated polyethylenimine-plasmid interleukin-15 complexes in murine models of lung metastasis. Cancer Sci. 2011; 102: 1403-1409. Ref.: https://goo.gl/hLQiCc 
86. Hattori Y, Arai S, Okamoto R, Hamada M, Kawano K, et al. Sequential intravenous injection of anionic polymer and cationic lipoplex of siRNA could effectively deliver siRNA to the liver. Int J Pharm. 2014; 476: 289-298. Ref.: https://goo.gl/ojVgE1

87. Hattori Y, Arai S, Kikuchi T, Hamada M, Okamoto R, et al. Optimization of siRNA delivery method into the liver by sequential injection of polyglutamic acid and cationic lipoplex. Pharmacol \& Pharma. 2015; 6: 302-310. Ref.: https://goo.gl/K6JkPs

88. Hattori Y, Yoshiike Y, Kikuchi T, Yamamoto N, Ozaki K, et al. Evaluation of injection route of anionic polymer for siRNA delivery into the liver by sequential injection of anionic polymer and cationic lipoplex of siRNA. J Drug Deliv Sci Tec. 2016; 35: 40-49. Ref.: https://goo.gl/VmbwSG

89. Tan GK, Tabata Y. Chondroitin-6-sulfate attenuates inflammatory responses in murine macrophages via suppression of NF-kappaB nuclear translocation. Acta Biomater. 2014; 10: 2684-2692. Ref.: https://goo.gl/uj47Ym

90. Stabler TV, Huang Z, Montell E, Vergés J, Kraus VB. Chondroitin sulphate inhibits NF-KB activity induced by interaction of pathogenic and damage associated molecules. Osteoarthritis Cartilage. 2017; 25: 166-174. Ref.: https://goo.gl/3GAnRV

91. Hattori $\mathrm{Y}$, Kikuchi T, Nakamura M, Ozaki K, Onishi H. Therapeutic effects of protein kinase N3 small interfering RNA and doxorubicin combination therapy on liver and lung metastases. Oncol Lett, in press. 